\title{
Entrepreneurial Attitudes Of MBA Students In The United States Relative To The CIS: The Case Of Armenia
}

\author{
Victor V. Claar, Ph.D., Hope College, USA \\ Vicki R. TenHaken, Hope Col lege, USA \\ Robery Frey, J.D., Grand Valley State University, USA
}

\begin{abstract}
This paper compares the entrepreneurial attributes of MBA students in Armenia to those in the United States. If entrepreneurial attributes are more learned cultural behaviors and not only inherent personality factors, business students in a recently-privatized economy such as Armenia would not score as high on an entrepreneurial personality index as would business students in the U.S. where both models of entrepreneurship and expectations of certain proactive characteristics in individuals entering the business world are widespread.
\end{abstract}

Keywords: entrepreneurship, proactive personality, emerging economies

\section{INTRODUCTION}

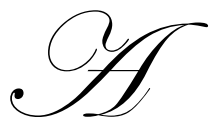

$\mathrm{n}$ entrepreneural attitude is defined as the desire and perceived likelihood of starting or running one's own business. Entrepreneurship is the process whereby an individual (or group of individuals) risks time and money in pursuit of opportunities to create value. Being entrepreneurial requires being creative and proactive in seeking out new opportunities. The characteristics that drive an individual to start or manage his or her own business are similar to the characteristics larger organizations are now looking for in employees. Because individuals with such traits can help bring about change and drive new growth opportunities and innovative business practices, organizations today are interested in finding a way to identify and hire employees with entrepreneurial characteristics.

A number of factors have been found to be associated with the likelihood of an individual becoming an entrepreneur. For instance, entrepreneurship tends to flourish in communities that foster risk-taking and minimize the penalties attached to failures. Having parents who encourage their children to explore new ideas and take risks is also beneficial: entrepreneurs typically have parents who urge them to be independent and take responsibility for their actions. Previous research has also identified several personal attributes associated with successful entrepreneurs. These attributes include a high need for achievement, a desire to act independently, high levels of self-confidence and self-esteem, and a willingness to sacrifice time spent on personal activities for commitment to their work. ${ }^{1}$ Other research has identified five personal attributes that consistently co-vary with entrepreneurship: need for achievement, locus of control, risk-taking propensity, tolerance for ambiguity, and Type-A behavior. ${ }^{2}$

Entrepreneurs also score high on proactive personality assessments. These are instruments that identify differences among people in the extent to which they take action to influence their environment. People with proactive personalities identify opportunities and act on them; they show initiative and persevere until they bring about change. ${ }^{3}$ Proactive behavior is behavior that directly alters environments; the proactive dimension of behavior is rooted in people's needs to manipulate and control the environment. People with a proactive personality will attempt to transform or surmount environments rather than adjust or acquiesce to them. ${ }^{4}$ The prototypic proactive personality is one who is relatively unconstrained by situational forces. Other people who would not be so classified are relatively passive: they react to, adapt to, and are shaped by their environments. Proactive people scan 
for opportunities, show initiative, take action and persevere until they reach closure by bringing about change. They are pathfinders who change their organization's mission or find and solve problems. ${ }^{5}$ People who are not proactive exhibit the opposite patterns: they fail to identify — let alone seize — opportunities to change things; they show little initiative and rely on others to be forces for change; they passively adapt to, and even endure, their circumstances.

The proactive personality index is a recent addition to the literature and appears to have the potential for providing further insight into the personality trait-entrepreneurship relationship. Such an instrument measures a person's disposition toward proactive behavior, and studies by J. Michael Crant and Thomas S. Bateman suggest that the proactive personality index may be useful in identifying people with the personality variables predictive of entrepreneurial behavior. ${ }^{6}$

This study will compare entrepreneurial attitudes of graduate business administration students in Armenia to those of MBA students in the United States. Both groups of students working on MBA degrees also have experience working in business. Our hypothesis is that proactive personality attributes are to a certain extent learned behaviors influenced by one's culture and not only inherent personality factors. If this is true, business students in a newly-privatizing economy such as Armenia would not score as high on the proactive personality index as would business students in the United States, where models of entrepreneurship and expectations of certain proactive behaviors in individuals entering the business world are widespread and result in a strong cultural influence toward entrepreneurial behavior.

\section{FRAMING THE ARMENIAN ENTREPRENEURIAL CONTEXT}

The Republic of Armenia is one of the formerly Soviet republics in transition. Set between the Black and Caspian Seas, it is bordered on the north by Georgia, on the south by Iran, on the east by Azerbaijan, and on the west by Turkey. Its population of about three million is extremely homogeneous: it is comprised almost entirely of ethnic Armenians.

Since the collapse of the Soviet Union, growth has been painful and difficult in the former Soviet republics. In fact, during the transition period, the average rate of growth among the transition economies has been less than zero. While some are advancing rapidly, others have experienced negative growth rates severe enough to pull the overall average into the negative range.

In the modern era, Armenia has known little political independence. Once a part of the Ottoman-Turk empire, it enjoyed a short-lived independence before joining the Soviet Union.

Today, Armenia is a poor country. Despite recent rapid rates of growth in GDP, Armenia's per capita annual income is nevertheless just $\$ 4,101$. Among its key exports are diamonds that have been brought into the country for polishing and agricultural products. Armenia is heavily dependent upon imported goods, including natural gas from Russia and Iran, oil, tobacco, and food. Armenia's annual trade deficit is about $\$ 500$ million. $^{7}$

Trade is expensive and difficult for Armenia. Due to ongoing diplomatic struggles with Turkey over the Armenian genocide, the border between Armenia and Turkey is closed. To the east of Armenia lies Azerbaijan, and that border is also closed, largely because of the ongoing Nagorno-Karabakh military conflict, as well as Azerbaijan's friendly ties with Turkey.

Until the recent military conflict between Russia and Georgia, Armenia's northern border with Georgia had been both open and reliable, and Armenia has relied heavily upon that route for most of the goods it imports from Russia. However, even that avenue for trade has been complicated in recent months because of difficult diplomatic, and now militaristic, relations between Russia and Georgia. In fact, at the time of this writing, Russia had again effectively closed its border with Georgia due to the ongoing armed mobilization. This represents a serious threat to the flow of goods to Armenia, inasmuch as most of its goods are imported from Russia. Yet it remains to be seen whether this will have an adverse effect upon Armenia, since Russia and Armenia have historically enjoyed a very friendly relationship. 
As with many former Soviet republics, Armenia does not have much in the way of an entrepreneurial track record. After all, the Soviet system is not one that readily offered many rewards in return for entrepreneurial behaviors, risk taking, or anticipating the needs of consumer-citizens. In fact, entrepreneurial attitudes in the former Soviet republics could often be channeled profitably into illegal activities, but not into the legally available opportunities. Therefore, one might expect little in the way of an entrepreneurial spirit among any of the former Soviet republics, including Armenia, since the Soviet system offered little incentive for it to grow and flourish.

Now that the Soviet experiment has come to a close, it is reasonble to wonder whether the current institutional arrangements offer more entrepreneurial possibilities than in the past. The evidence is mixed. On one hand Armenia, for several reasons, is one of the most economically free nations in the European region. First, and probably most importantly, the monetary authority is doing a magnificent job of both stabilizing the economy and of regulating the local banking industry. Second, in many ways, Armenia is a place where it is extremely simple to get things done. There is little monitoring of business activities, and there are very few bureaucratic hoops that a new business must jump through in order to get things done.

Further, according to a recent assessment by the World Bank, Armenia's business environment is the best among the Commonwealth of Independent States (CIS) nations. For example, the study states that it takes just 25 days and 10 steps to register a new company in Armenia; it requires 115 days to accomplish the same thing in Azerbaijan. ${ }^{8}$ Hence, at least along these dimensions, Armenia affords wonderful opportunites for entrepreneuriallyinclined people to try new things.

On the other hand, though, there are areas in which the current structures in Armenia can possibly discourage entrepreneurial risk-taking. For example, due in part to a relatively weak judiciary system that may be influenced at times by the executive branch of the government, there is not full assurance that contracts will be entirely enforceable. In such a climate, it is difficult for a budding entrepreneur-even of the most risk-loving variety - to make a substantial investment in anything if the return is imperiled by an unreliable judicial system.

Another possible obstacle to the entrepreneurial spirit is the not uncommon degree of corruption present in some parts of government and also the perception by Armenian citizens that the government is corrupt. According to a recent survey conducted by Transparency International, two-thirds of Armenians surveyed believe that the degree of corruption in Armenia has increased in recent years. And the most recent release of Transparency International's Corruption Perception Index states that Armenia ranks 93rd out of the 161 ranked nations. ${ }^{9}$

A third possible impediment to the entrepreneurial spirit in Armenia is its hybrid style of government-a mix of both democracy and authoritarianism, according to the Economist Intelligence Unit (EIU). While the EIU rates Armenia quite highly in terms of personal freedoms, as described above, the EIU also rates Armenia low based upon its electoral process, as well as the effectiveness of its government. ${ }^{10}$

Nevertheless, Armenia does appear to be moving forward in the area of governmental effectiveness. In last year's World Bank Worldwide Governance Report, the bank placed Armenia in the 41st percentile of a distribution of 200 nations according to the quality of their governments. While this at first might seem low, it is a considerable improvement over its placement at the 29 th percentile in a related 1998 survey. ${ }^{11}$

In light of its Soviet history, as well as its current mixed climate where entrepreneurship is concerned, Armenia presents an interesting opportunity to explore how entrepreneurial/proactive attitudes compare between Western and transition economies in groups that have both entered into business careers and programs of business study. Perhaps business students in a newly-privatizing economy such as Armenia would not score as high on a proactive personality index as would business students in the United States, where both models of entrepreneurship and expectations of certain proactive characteristics in individuals entering the business world are relatively widespread. However, if such proactive attributes are indeed inherent personality factors rather than primarily derived from one's culture, there should be no difference in the results between the Armenian and U.S. graduate students. 


\section{METHODOLOGY}

An instrument containing 17 questions that measure proactive personality (Appendix A) was administered to $105 \mathrm{MBA}$ students at a state university in the United States and to 28 first-year MBA students at an accredited Western-style graduate school in Armenia. This self-report measure of proactive behavior was developed by Bateman and Crant to measure a person's disposition toward proactive behavior as a general construct that predicts behaviors intended to effect change. ${ }^{12}$

An individual's total score will range between 17 and 119 on this instrument. The higher one's score, the stronger the proactive personality. Previous work by Bateman and Crant has determined that scores above 85 indicate fairly high proactivity. In a previous study of $134 \mathrm{MBA}$ students in the United States, the average score was 90.7. ${ }^{13}$ Virtually all of these MBA students had full-time work experience, with an average of 3.7 years. The sample was 75 percent male, and the average age was 27.5 .

\section{RESULTS}

The instrumental overall average scores of each group, as well as the average of each group on each item in the instrument, are presented in Appendix B. The first two columns, with the heading "GVSU," give the mean response and standard deviation of each response from the U.S. students, while the next two columns present the parallel information for the MBA students in Armenia, labeled "AUA."

The scores of U.S. students taking this instrument in 2008 were comparable to the results of the MBA students in the 1993 study: the mean overall score was 89.294, with a minimum score of 58 and a maximum of 113. This confirms that MBA students in the U.S. are proactive, since Bateman and Crant have determined scores above 85 indicate a high proactive personality. Individual questions with particularly high ratings (mean scores of 5.5 or higher on a 7-point Likert-type scale) include:

- $\quad$ Nothing is more exciting than seeing my ideas turn into reality. (6.076)

- I I am constantly on the lookout for new ways to improve my life. (6.029)

- $\quad$ If I see someone in trouble, I help out in any way I can. (5.857)

- I I am always looking for better ways to do things. (5.762)

- $\quad$ If I see something I don’t like, I fix it. (5.695)

The overall scores of the Armenian MBA students taking this instrument in 2007, though slightly lower, were statistically indistinguishable from the results of the U.S. MBA students in both the 1993 study and our 2008 study; the mean overall score was 88.576 , with a minimum score of 56 and a maximum of 112 . This indicates that business students in Armenia - even with a fairly limited experience with or exposure to an entrepreneurial environment - score high on the proactive personality scale (again, scores above 85 indicate high proactivity). Individual questions with particularly high ratings for the Armenian group include:

- $\quad$ Nothing is more exciting than seeing my ideas turn into reality. (6.464)

- I I am constantly on the lookout for new ways to improve my life. (6.036)

- $\quad$ I am always looking for better ways to do things. (6.000)

- $\quad$ If I see someone in trouble, I help out in any way I can. (6.000)

- I love being a champion for my ideas, even against others' opposition. (5.769)

- $\quad$ If I believe in an idea, no obstacle will prevent me from making it happen. (5.607)

- $\quad$ No matter what the odds, if I believe in something, I will make it happen. (5.571)

Since the overall averages for the two groups were close, yet the scores on some individual items appeared to be quite different, we tested to see whether there were any statistically significant differences between the scores on each item between the two groups. The final column in the table shown in Appendix B gives the $t$ statistic resulting from testing for statistically significant differences between the means of these two groups on each item in 
the inventory. While the difference in total score averages are less than one (0.718), there are some interesting, statistically-significant differences for individual items.

Items significant at the $\alpha=0.1$ level are:

- $\quad$ I feel driven to make a difference in my community and maybe the world. (U.S. group is higher.)

- $\quad$ Nothing is more exciting than seeing my ideas turn into reality. (Though both groups score high on this item and it was the highest scoring item for each group, the Armenian students scored significantly higher.)

- I I am great at turning problems into opportunities. (U.S. group is higher.)

Items significant at the $\alpha=0.05$ level are:

- I love being a champion for my ideas, even against others' opposition. (Armenian group is higher.)

- $\quad$ If I believe in an idea, no obstacle will prevent me from making it happen. (Armenian group is higher.)

And one item was significant at the $\alpha=0.01$ level:

- $\quad$ If I see something I don’t like, I fix it. (U.S. group higher.)

Summarizing these differences by country, following are the items where U.S. students scored significantly higher than the Armenian students:

- $\quad$ I feel driven to make a difference in my community and maybe the world. (Significant at the $\alpha=0.1$ level.)

- I I am great at turning problems into opportunities. (Significant at the $\alpha=0.1$ level.)

- If I see something I don't like, I fix it. (Significant at the $\alpha=0.01$ level.)

Items where Armenian students scored significantly higher than U.S. students are:

- Nothing is more exciting than seeing my ideas turn into reality. (Significant at the $\alpha=0.1$ level)

- I love being a champion for my ideas, even against others' opposition. (Significant at the $\alpha=0.05$ level)

- If I believe in an idea, no obstacle will prevent me from making it happen. (Significant at the $\alpha=0.05$ level)

\section{DISCUSSION AND CONCLUSION}

It is interesting that both groups of MBA students scored similarly overall on the proactive personality instrument, yet had such strong differences on individual items. One possible explanation for the difference is that, on average, U.S. MBA students are relatively reluctant to champion their individual ideas but believe the world is a place that can be changed if one tries. The Armenian students clearly are more excited - and perhaps more persistent - about advocating their personal ideas, but perhaps believe the world around them is difficult to change.

For example, Armenian MBA students scored significantly higher on items that specifically mention their ideas, such as "Nothing is more exciting than seeing $\boldsymbol{m y}$ ideas turn into reality," and "I love being a champion for my ideas, even against others' opposition," and "If I believe in an idea, no obstacle will prevent me from making it happen" (bold and italics added for emphasis).

In contrast, U.S. MBA students scored much higher on items that refer to being a catalyst for hopeful change, such as "I feel driven to make a difference in my community and maybe the world," and "I am great at turning problems into opportunities," and "If I see something I don't like, I fix it." Given the perception, stated above, that two-thirds of Armenians surveyed believe the degree of corruption in Armenia has increased in recent years, perhaps Armenians have less hope to be a force for change than do their western counterparts. 
Regardless of the differences, both Armenian and U.S. MBA students exhibit very strong overall proactive, entrepreneurial attitudes, lending evidence to the conclusion that proactive personality attributes may be based more on inherent personality factors rather than strictly cultural learning. However, how those attributes are then demonstrated or expressed may be driven by cultural realities. Thus there is much reason to be hopeful for entrepreneurship to emerge in the CIS nations.

\section{AUTHOR INFORMATION}

Victor V. Claar, Ph.D., West Virginia University, is an Associate Professor of Economics at Hope College. He spent a recent sabbatical year as a Fulbright Scholar at the American University of Armenia, lecturing to MBA students and students pursuing a master's degree in political science. He serves on the board of Black River Public School, an innovative charter school in Holland, Michigan. Dr. Claar's articles appear in refereed economics journals such as Applied Economics and Public Finance Review and he is coauthor of the book Economics in Christian Perspective (IVP Academic). He is writing a new book about fair trade.

Vicki TenHaken is an Associate Professor of Management at Hope College and a 2007 Republic of Poland Fulbright Scholar. Her work in the areas of leadership, strategy, and entrepreneurship - much of it with an international focus - has appeared in several refereed journals. She is co-director of the Hope College-Meiji Gakuin (Japan) Global Management Seminar. Ms. TenHaken, a former business executive with experience in strategy, business development, marketing and human resources, has taught Management courses since 2000 including Management Theory, Human Resource Management, Managing for Environmental Sustainability, and the capstone Management Seminar. She has just completed a handbook for new managers.

Robert Frey, Assistant Professor of Management at Seidman College of Business, Grand Valley State University, teaches Global Strategy, Business Law, and Business, Society and Ethics, and serves as Director of the Business Ethics Center. Previously, Mr. Frey was the Chief Legal Officer and then Executive Vice President of Global Operations for Whirlpool Corporation living in Brazil, Japan and Singapore, and then President of Herman Miller International and Executive Vice President of Herman Miller, Inc. Mr. Frey currently serves on the Board of Directors of Energy Conversion Devices, Inc., and as Chairman of its Governance Committee. 


\section{Appendix A: Proactive Personality Survey Instrument}

Please respond to each of the 17 statements using the following scale:

$1=$ Strongly disagree

$2=$ Moderately disagree

3 = Slightly disagree

$4=$ Neither agree or disagree

$5=$ Slightly agree

$6=$ Moderately agree

$7=$ Strongly agree

1. I am constantly on the lookout for new ways to improve my life.

\begin{tabular}{|c|c|c|c|c|c|}
\hline 1 & 2 & 3 & 4 & 5 & 6 \\
\hline 1 & 2 & 3 & 4 & 5 & 6 \\
\hline
\end{tabular}

3. I tend to let others take the initiative to start new projects.

$\begin{array}{lllllll}1 & 2 & 3 & 4 & 5 & 6 & 7 \\ 1 & 2 & 3 & 4 & 5 & 6 & 7 \\ 1 & 2 & 3 & 4 & 5 & 6 & 7\end{array}$

6. Nothing is more exciting than seeing my ideas turn into reality.

7. If I see something I don't like, I fix it.

8. No matter what the odds, if I believe in something, I will make it happen.

9. I love being a champion for my ideas, even against others' opposition.

10. I excel at identifying opportunities.

11. I am always looking for better ways to do things.

12. If I believe in an idea, no obstacle will prevent me from making it happen.

13. I love to challenge the status quo.

14. When I have a problem, I tackle it head-on.

15. I am great at turning problems into opportunities.

16. I can spot a good opportunity long before others can.

$\begin{array}{lllllll}1 & 2 & 3 & 4 & 5 & 6 & 7 \\ 1 & 2 & 3 & 4 & 5 & 6 & 7\end{array}$

$\begin{array}{lllllll}1 & 2 & 3 & 4 & 5 & 6 & 7\end{array}$

$\begin{array}{lllllll}1 & 2 & 3 & 4 & 5 & 6 & 7 \\ 1 & 2 & 3 & 4 & 5 & 6 & 7\end{array}$

$\begin{array}{lllllll}1 & 2 & 3 & 4 & 5 & 6 & 7\end{array}$

$\begin{array}{lllllll}1 & 2 & 3 & 4 & 5 & 6 & 7 \\ 1 & 2 & 3 & 4 & 5 & 6 & 7 \\ 1 & 2 & 3 & 4 & 5 & 6 & 7\end{array}$

$\begin{array}{lllllll}1 & 2 & 3 & 4 & 5 & 6 & 7\end{array}$

$\begin{array}{lllllll}1 & 2 & 3 & 4 & 5 & 6 & 7\end{array}$

17. If I see someone in trouble, I help out in any way I can.

$\begin{array}{lllllll}1 & 2 & 3 & 4 & 5 & 6 & 7\end{array}$




\section{Appendix B: Empirical Findings}

1. I am constantly on the lookout

\begin{tabular}{|c|c|c|c|c|}
\hline $\boldsymbol{G} \boldsymbol{V}_{\boldsymbol{s}}$ & & $\boldsymbol{A U}$ & & \\
\hline $\begin{array}{c}\text { Avg. } \\
\text { Score } \\
(N=105)\end{array}$ & $\begin{array}{l}\text { Std. } \\
\text { Dev. }\end{array}$ & $\begin{array}{c}\text { Avg. } \\
\text { Score } \\
(N=28)\end{array}$ & $\begin{array}{l}\text { Std. } \\
\text { Dev. }\end{array}$ & $t$ \\
\hline 6.029 & 0.975 & 6.036 & 1.374 & -0.031 \\
\hline
\end{tabular}

for new ways to improve my life.

2. I feel driven to make a difference in my community and maybe the world.

3. I tend to let others take the initiative to start new projects.

4. Wherever I have been, I have been a powerful force for constructive change.

5. I enjoy facing and overcoming obstacles to my ideas.

6. Nothing is more exciting than seeing my ideas turn into reality.

7. If I see something I don't like, I fix it.

8. No matter what the odds, if I believe in something, I will make it happen.

9. I love being a champion for my ideas, even against others' opposition.

10. I excel at identifying opportunities.

11. I am always looking for better ways to do things.

\begin{tabular}{|c|c|c|c|c|}
\hline 5.467 & 1.177 & 4.964 & 1.319 & $1.956^{*}$ \\
\hline 3.667 & 1.609 & 3.444 & 1.739 & 0.629 \\
\hline 4.731 & 1.125 & 4.704 & 1.489 & 0.104 \\
\hline 5.333 & 1.377 & 5.214 & 1.641 & 0.390 \\
\hline 6.076 & 0.895 & 6.464 & 1.201 & $-1.888^{*}$ \\
\hline 5.695 & 1.178 & 4.964 & 1.644 & $2.669 * * *$ \\
\hline 5.202 & 1.403 & 5.571 & 1.451 & -1.228 \\
\hline 5.135 & 1.449 & 5.769 & 1.336 & $-2.028 * *$ \\
\hline 5.229 & 1.146 & 5.179 & 1.335 & 0.198 \\
\hline 5.762 & 1.070 & 6.000 & 1.122 & -1.036 \\
\hline 4.971 & 1.355 & 5.607 & 1.449 & $-2.174 * *$ \\
\hline 5.087 & 1.308 & 4.893 & 1.618 & 0.660 \\
\hline 5.352 & 1.109 & 5.000 & 1.388 & 1.414 \\
\hline 4.952 & 1.147 & 4.444 & 1.553 & $1.901 *$ \\
\hline 4.750 & 1.197 & 4.321 & 1.335 & 1.641 \\
\hline 5.857 & 1.023 & 6.000 & 1.054 & -0.652 \\
\hline 89.29 & & 88.576 & & \\
\hline
\end{tabular}

12. If I believe in an idea, no obstacle will prevent me from making it happen.

13. I love to challenge the status quo.

.

14. When I have a problem, I tackle it head-on.

15. I am great at turning problems into opportunities.

16. I can spot a good opportunity long before others can.

17. If I see someone in trouble, I help out in any way I can.

Total $=$

$*, * *$, and $* * *$ indicate significance at the $\alpha=0.1,0.05$, and 0.01 levels. 
${ }^{1}$ D. Hellriegel, S. E. Jackson and J. W. Slocum, Jr., "Management," $8^{\text {th }}$ Edition, South-Western College Publishing (1999), pp. $150-152$.

${ }^{2}$ R. H. Brockhaus and P.S. Horwitz, "The Psychology of the Entrepreneur," The Art and Science of Entrepreneurship. Cambridge, MA. (1986), pp. 25-48. (NOTE: Type-A behavior is a set of characteristics that includes being impatient, highly competitive, driven by deadlines, and aggressive.)

${ }^{3}$ J. M. Crant, "The Proactive Personality Scale as a Predictor of Entrepreneurial Intentions," Journal of Small Business Management Vol. 34 (July 1996), pp. 42-49.

${ }^{4}$ S. Maddi, Personality Theories: A Comparative Analysis, Dorsey Press, Chicago, IL (1989)

${ }^{5}$ H. Leavitt, Managerial Psychology: Managing Behavior in Organizations, Dorsey Press, Chicago, IL (1988).

${ }^{6}$ T. S. Bateman and J. M. Crant, "The Proactive Component of Organizational Behavior: A Measure and Correlates," Journal of Organizational Behavior, Vol. 14, No. 2. (March 1993), pp. 103-118.

${ }^{7}$ All figures in this section taken from Kane, Tim, Kim R. Holmes, and Mary Anastacia O'Grady, 2007 Index of Economic Freedom, Heritage Foundation and the Wall Street Journal, Washington, D.C. and New York (2007).

${ }^{8}$ Markarian, Atom, “Armenia's Business Environment 'Best in CIS,"” Armenialiberty.org, September 21, 2005.

${ }^{9}$ Danielyan, Emil and Shakeh Avoyan, “Armenians See Increased Corruption, Shows New Survey,” Armenialiberty.org, January 31, 2007.

${ }^{10}$ Stamboltsian, Gevorg, "Economist Intelligence Unit Ranks Armenia 110th by Its Degree of Democracy," Armenialiberty.org, November 21, 2006.

${ }^{11}$ Danielyan, Emil, "World Bank Survey Shows Improved Governance in Armenia," Armenialiberty.org, September 15, 2006.

${ }^{12}$ T. S. Bateman and J. M. Crant, Op. cit. pp. 111-116. On the basis of their study, Bateman and Crant concluded that this revised 17-item proactive scale taps a single broad construct of high internal reliability. Though this study does not offer conclusive evidence that the proactive disposition caused people to engage in proactive achievement or actual transformational behaviors, to a significant degree, study participants were inferring from their past behavior when completing the self-assement of proactive behavior.

${ }^{13}$ Ibid. p. 108. 
NOTES 